\title{
LINK-A IncRNA is upregulated in osteosarcoma and regulates migration, invasion and stemness of osteosarcoma cells
}

\author{
YAO KONG, ZHIKUI NIE, HONGMIN GUO and CAO MA \\ Department of Osteoarthrosurgery, Jining First People's Hospital, Jining, Shandong 272100, P.R. China
}

Received August 28, 2018; Accepted June 13, 2019

DOI: $10.3892 / \mathrm{ol} .2020 .11367$

\begin{abstract}
The present study aimed to investigate the involvement of long intergenic non-coding RNA for kinase activation (LINK-A) long non-coding RNA (lncRNA) in osteosarcoma. Plasma levels of LINK-A lncRNA and transforming growth factor $\beta 1$ (TGF- $\beta 1$ ) were measured by reverse transcription-quantitative polymerase chain reaction and ELISA, respectively. Correlation between LINK-A IncRNA and TGF- $\beta 1$ was analyzed by Pearson correlation coefficient. LINK-A IncRNA and TGF- $\beta 1$ were upregulated in patients with osteosarcoma compared with healthy controls. LINK-A lncRNA and TGF- $\beta 1$ were positively correlated in the two groups. LINK-A IncRNA short hairpin RNAs (shRNAs) were transfected into osteosarcoma cell lines and Transwell migration assay, Matrigel invasion assay and flow cytometry were used to evaluate cell migration, invasion and stemness, respectively. Effects of LINK-A lncRNA silencing and overexpression on TGF- $\beta 1$ expression were analyzed by western blotting. LINK-A lncRNA shRNA silencing inhibited, whereas TGF- $\beta 1$ treatment promoted cell migration, invasion and stemness. LINK-A lncRNA silencing inhibited TGF- $\beta 1$ expression, whereas TGF- $\beta 1$ treatment had no effects on LINK-A IncRNA expression. TGF- $\beta 1$ reduced the inhibitory effects of LINK-A lncRNA knockdown on cancer cell migration, invasion and stemness. These data indicated that LINK-A lncRNA is upregulated in osteosarcoma and may regulate migration, invasion and stemness of osteosarcoma cells through TGF- $\beta 1$.
\end{abstract}

\section{Introduction}

Osteosarcoma is a type of primary bone tumor that affects approximately four out of one million people in some

Correspondence to: Dr Cao Ma, Department of Osteoarthrosurgery, Jining First People's Hospital, 6 Jiankang Road, Shizhong, Jining, Shandong 272100, P.R. China

E-mail: pjiek57@163.com

Key words: osteosarcoma, long intergenic non-coding RNA for kinase activation, long non-coding RNA, transforming growth factor $\beta$, migration, invasion, stemness countries, such as Argentina (1). With the efforts made in treatment of osteosarcoma, survival rate and time of patients with this disease has been markedly improved (2). However, no further significant improvement has been achieved since the 1990s and the overall survival is still poor $(3,4)$. Patients with early stage osteosarcoma usually exhibit satisfactory treatment outcomes, following radical resection. Once distant tumor metastasis occurs surgical resection is not applicable and survival is extremely low (5). At present, active treatment after early diagnosis is still the key to treatment of patients with osteosarcoma.

Transforming growth factor $\beta$ (TGF- $\beta$ ) is a multifunctional cytokine that regulates the activation of different regulatory proteins and downstream substrates that are involved in cell differentiation, proliferation, chemotaxis and activation of immune cells $(6,7)$. TGF- $\beta$ is generally considered as a double-edged sword in the development of most types of human malignancies (8); activation of TGF- $\beta$ signaling inhibits cancer cell proliferation at the initiation of tumorigenesis but promotes tumor cell migration and invasion by mediating epithelial-mesenchymal transition (9). A growing body of literature has revealed that TGF- $\beta$ signaling achieves signal transduction in cancer biology not only by interacting with regulatory proteins, but also through crosstalk with non-coding RNAs, such as long non-coding RNAs (lncRNAs) (10,11). Long intergenic non-coding RNA for kinase activation (LINK-A) lncRNA is a recently characterized oncogenic lncRNA in triple-negative breast cancer and ovarian carcinoma $(12,13)$. The present study demonstrated that LINK-A IncRNA was upregulated in osteosarcoma and may regulate migration, invasion and stemness of osteosarcoma cells through TGF- $\beta 1$.

\section{Materials and methods}

Human tissues and cell lines. Plasma samples were collected from 66 patients with osteosarcoma and 54 healthy volunteers who were admitted by Jining First People's Hospital (Shizhong, China) between January 2014 and April 2018. The 66 patients with osteosarcoma included 30 males and 26 females, aged

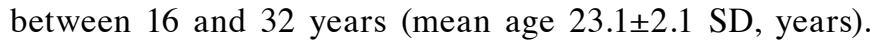
There were 12 cases in stage I, 14 cases in stage II, 16 cases in stage III and 24 cases in stage IV. The following inclusion criteria were used: i) Patients diagnosed by biopsies; ii) patients who were diagnosed for the first time; iii) patients 
who fully understood the experimental protocol and signed informed consent. The exclusion criteria were: i) Patients who were diagnosed with multiple diseases; ii) patients who were treated within 6 months before sample collection. The 54 healthy volunteers included 29 males and 25 females, aged between 17 and 30 years (mean age, $22.9 \pm 2.4$ years). The two groups had similar age and sex distributions.

MG-63 and U2OS osteosarcoma cell lines were purchased from the American Type Tissue Collection (ATCC; Manassas, VA, USA). Eagle's minimum essential medium (MEM; cat. no. 30-2003; ATCC) supplemented with 10\% heat-inactivated fetal bovine serum (FBS, Sigma-Aldrich; Merck KGaA, Darmstadt, Germany) was used to cultivate cancer cells under normal conditions $\left(37^{\circ} \mathrm{C} ; 5 \% \mathrm{CO}_{2}\right)$. In cases of TGF- $\beta 1$ treatment, cells were treated in medium containing exogenous TGF- $\beta 1$ (Sigma-Aldrich; Merck KGaA) at doses of 10, 20, 30, 40 and $50 \mathrm{ng} / \mathrm{ml}$ for $24 \mathrm{~h}$ prior to further experiments.

Cell transfection. Vectors (pcDNA3.1) containing LINK-A lncRNA short hairpin RNA (shRNA 5'-AAAAGCTTC TCTCACCCTTCAAATTGGATCCAATTTGAAGGGTGAG AGAAGC-3') were designed and synthesized by Shanghai GeneChem Co., Ltd. (Shanghai, China). MISSION shRNA Control Vector was purchased from Sigma-Aldrich (cat. no. SHC001; Merck KGaA). LINK-A (NCBI ID, NR_015407.1) lncRNA overexpression vectors (pcDNA3.1) and empty vectors (pcDNA3.1) were provided by Shanghai Sangong Pharmaceutical Co., Ltd. (Shanghai, China). Lipofectamine ${ }^{\circledR} 2000$ reagent (cat. no. 11668-019; Invitrogen; Thermo Fisher Scientific, Inc., Waltham, MA, USA) was used to transfect $15 \mathrm{nM}$ vectors into $5 \times 10^{5} \mathrm{MG}-63$ and U2OS cells. Transfections were performed at $37^{\circ} \mathrm{C}$ for $6 \mathrm{~h}$. Non-transfected cells were used as control cells. Cells transfected with empty vectors were used as negative transfection control cells. Transfection efficiency was determined by reverse transcription-quantitative polymerase chain reaction (RT-qPCR). Cells were harvested $24 \mathrm{~h}$ post-transfection prior to subsequent experiments.

$R T-q P C R$. Total RNA extraction from $0.3 \mathrm{ml}$ plasma and in vitro cultivated cells $\left(1 \times 10^{5}\right)$ was performed using Monarch $^{\circledR}$ Total RNA Miniprep kit (New England Biolabs, Inc., Ipswich, MA, USA). Reverse transcription was performed using High-Capacity cDNA Reverse Transcription Kit (Thermo Fisher Scientific, Inc.) to synthesize cDNA. PCR reaction systems were prepared using Luna ${ }^{\circledR}$ Universal One-Step RT-qPCR kit (SYBR; New England Biolabs, Inc.). CFX96 Touch $^{\mathrm{TM}}$ Real-Time PCR detection system (Bio-Rad Laboratories, Inc., Hercules, CA, USA) was used to perform all qPCR reactions. The qPCR thermocycling conditions were as follows: Initial denaturation at $95^{\circ} \mathrm{C}$ for $52 \mathrm{sec}$, followed by 40 cycles of $95^{\circ} \mathrm{C}$ for $14 \mathrm{sec}$ and $58.5^{\circ} \mathrm{C}$ for $26 \mathrm{sec}$. Sequences of primers used were as follows: Human LINK-A, forward 5'-TTCCCCCATTTTTCCTTTTC-3', reverse 5'-CTC TGGTTGGGTGACTGGTT-3'; $\beta$-actin, forward 5'-GAC CTCTATGCCAACACAGT-3', reverse 5'-AGTACTTGC GCTCAGGAGGA3'. This experiment was performed in triplicate, and all quantitation cycle values were normalized to $\beta$-actin and relative expression was quantified by the $2^{-\Delta \Delta \mathrm{Cq}}$ method (14).
ELISA. TGF- $\beta 1$ in $0.3 \mathrm{ml}$ plasma was detected using Human TGF- $\beta 1$ Quantikine ELISA Kit (cat. no. DB100B; R\&D Systems, Inc.). All operations were performed following manufacturer's protocol. Optical density values were detected at $540 \mathrm{~nm}$.

Transwell migration and invasion assays. QCM Chemotaxis Cell Migration assay, 24-well (8 $\mu \mathrm{m})$, colorimetric (cat. no. ECM508; Sigma-Aldrich; Merck KGaA), and QCM ECMatrix Cell Invasion assay, 24-well (8 $\mu \mathrm{m})$, colorimetric (cat. no. ECM550; Sigma-Aldrich; Merck KGaA), were used. In cases of TGF- $\beta 1$ treatment, $10 \mathrm{ng} / \mathrm{ml}$ TGF- $\beta 1$ (Sigma-Aldrich; Merck KGaA) was added to the MEM according to manufacturer's instructions. Briefly, serum-free cell suspensions $\left(3 \times 10^{4}\right.$ cells $\left./ \mathrm{ml}\right)$ were made and $0.1 \mathrm{ml}$ of a cell suspension was transferred to the upper chamber of the Transwell plates. Culture medium containing 20\% FBS was added into the lower chamber. Cells were cultivated for $24 \mathrm{~h}$ at $37^{\circ} \mathrm{C}$. Membranes were cleaned using a cotton swab, followed by staining with $0.5 \%$ crystal violet (Sigma-Aldrich; Merck KGaA) for $20 \mathrm{~min}$ at room temperature. This protocol was used for both invasion and migration assays; prior to the invasion assay the upper chamber was coated with Matrigel (cat. no. 356234; EMD Millipore, Billerica, MA, USA). The experiments were performed in triplicate. Cells were observed and counted under Olympus CX43 light microscope (x40 magnification).

Flow cytometry. MG-63 and U2OS cells $\left(3 \times 10^{5}\right)$ were trypsinized, harvested, and incubated with phycoerythrin (PE)-conjugated CD133 (1:1,500; cat. no. 566593; BD Biosciences, San Jose, CA, USA) or immunoglobulin (Ig) G1-PE antibody (1:1,500; cat. no. 130-093-193; Miltenyi Biotec, Bergisch Gladbach, Germany) in buffer (1X PBS + 0.5\% BSA, Sigma-Aldrich; Merck KGaA) for $20 \mathrm{~min}$ at $4^{\circ} \mathrm{C}$. Signals were detected using a FACS Aria flow cytometry system (BD Immunocytometry Systems, San Jose, CA, USA) and processed by Cell Quest software v5.1 (BD Biosciences). This experiment was performed in triplicate.

Western blotting. Total protein was extracted from in vitro cultivated cells $\left(1 \times 10^{5}\right)$ using the Total Protein Extraction kit provided by Merck KGaA (cat. no. 2140). Protein concentrations were measured using BCA assay (Sangon Biotech Co., Ltd., Shanghai, China). Proteins (30 $\mu \mathrm{g}$ per lane) were separated by $12 \%$ SDS-PAGE and gel transferred to PVDF membranes. Blocking was performed using PBS containing $5 \%$ skimmed milk for $1 \mathrm{~h}$ at room temperature. Primary antibodies against TGF- $\beta 1$ (cat. no. ab9758; rabbit anti-human; 1:1,200; Abcam, Shanghai, China) and GAPDH (ab9485; rabbit anti-human; 1:1,400; Abcam) were used at $4^{\circ} \mathrm{C}$ for $18 \mathrm{~h}$. The secondary antibody was horseradish peroxidase-conjugated goat anti-rabbit IgG (cat. no. MBS435036; 1:1,000; MyBioSource, Inc., San Diego, CA, USA). ECL ${ }^{\mathrm{TM}}$ western blotting reagents (Sigma-Aldrich; Merck KGaA) were added to develop signals. ImageJ software v.1.46 (National Institutes of Health, Bethesda, MD, USA) was used for densitometry analysis. TGF- $\beta 1$ expression was normalized to GAPDH. This experiment was performed in triplicate. 

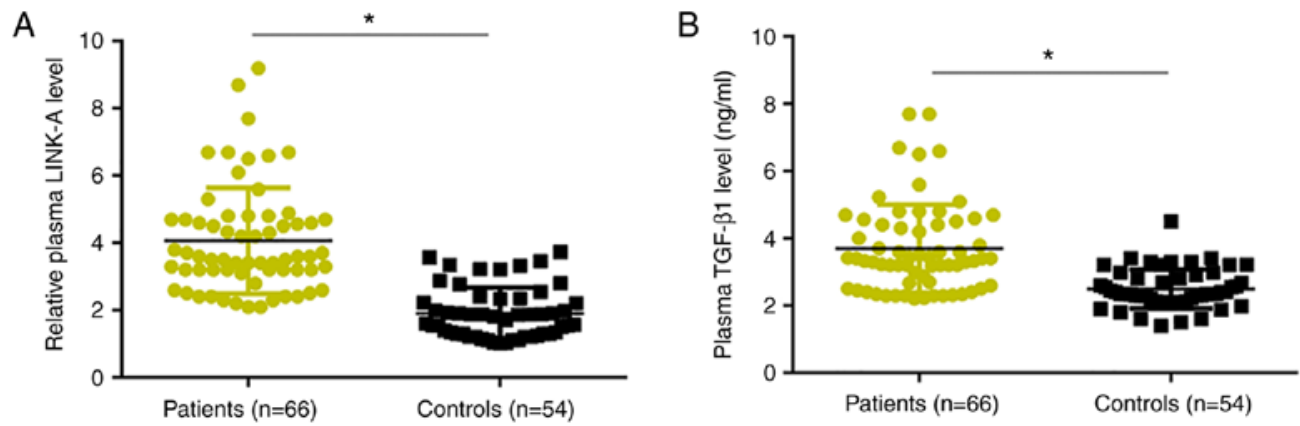

Figure 1. LINK-A lncRNA and TGF- $\beta 1$ are upregulated in patients with osteosarcoma compared with healthy controls. (A and B) Compared with healthy controls, plasma levels of (A) LINK-A lncRNA (B) and TGF- $\beta 1$ were significantly increased in patients with osteosarcoma. "P<0.05. LINK-A, long intergenic non-coding RNA for kinase activation; lncRNA, long non-coding RNA; TGF- $\beta 1$, transforming growth factor $\beta 1$.
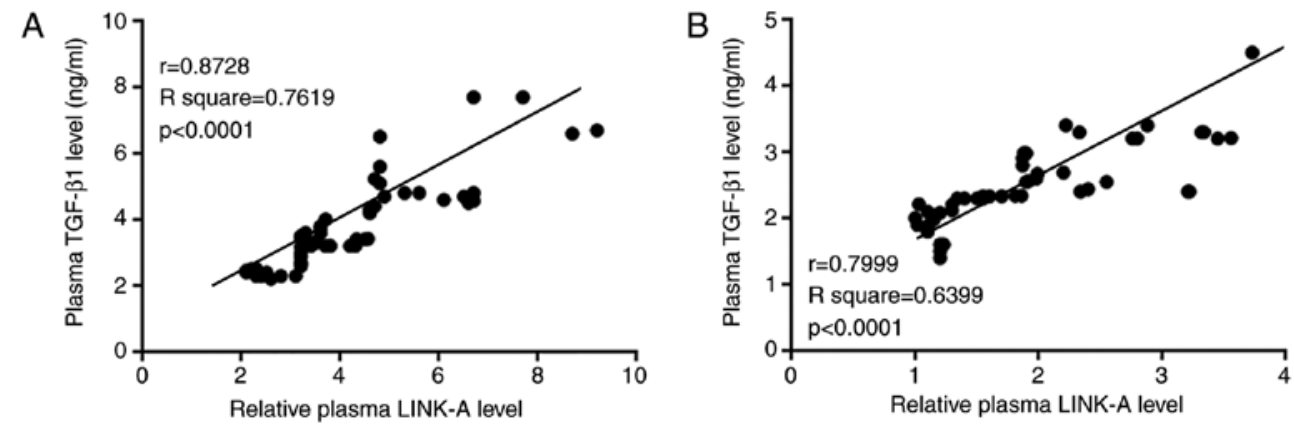

Figure 2. Plasma LINK-A lncRNA and TGF- $\beta 1$ are positively correlated in both patients with osteosarcoma and healthy controls. (A and B) Plasma levels of LINK-A lncRNA and TGF- $\beta 1$ were positively correlated in (A) patients with osteosarcoma and (B) healthy controls. LINK-A, long intergenic non-coding RNA for kinase activation; lncRNA, long non-coding RNA; TGF- $\beta 1$, transforming growth factor $\beta 1$.

Statistical analysis. Data are presented as the mean \pm standard deviation; values were calculated and processed using GraphPad Prism 6 software (GraphPad Software, Inc., La Jolla, CA, USA). Pearson correlation coefficient was used for correlation analysis. Student's t-test was used for comparisons between two groups. One-way analysis of variance followed by Tukey test was used for comparisons among multiple groups. Diagnostic analysis was performed by receiver operating characteristics (ROC) curve. $\mathrm{P}<0.05$ was considered to indicate a statistically significant difference.

\section{Results}

LINK-A IncRNA and TGF- $\beta 1$ are upregulated in patients with osteosarcoma compared with healthy controls. RT-qPCR results revealed that, compared with healthy controls, plasma levels of LINK-A IncRNA were significantly increased in patients with osteosarcoma (Fig. 1A). Similarly, ELISA results demonstrated that plasma levels of TGF- $\beta 1$ were significantly higher in patients with osteosarcoma compared with levels in healthy controls (Fig. 1B).

Plasma LINK-A IncRNA and TGF- $\beta 1$ are positively correlated in patients with osteosarcoma and in healthy controls. Pearson correlation coefficient analysis demonstrated that plasma levels of LINK-A lncRNA and TGF- $\beta 1$ were positively correlated in both osteosarcoma patients (Fig. 2A) and in healthy controls (Fig. 2B).

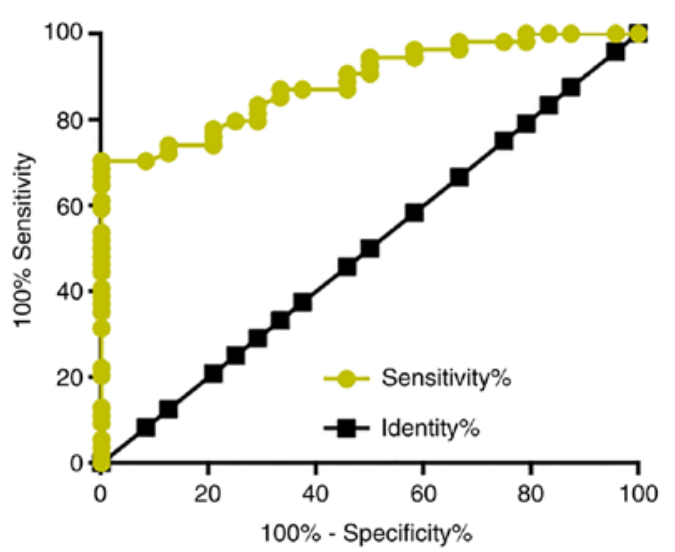

Figure 3. Plasma LINK-A lncRNA has diagnostic potentials for early stage osteosarcoma. ROC curve was performed to analyze the diagnostic value of LINK-A for osteosarcoma. Patients with early stage osteosarcoma were true positive cases and the healthy controls were true negative cases. LINK-A, long intergenic non-coding RNA for kinase activation; lncRNA, long non-coding RNA.

Plasma LINK-A lncRNA has diagnostic potentials for early stage osteosarcoma. Among the 66 patients with osteosarcoma, there were 26 cases in stage I and II, which are considered as the early stages of cancer development. ROC curve analysis was performed to evaluate the diagnostic value of plasma LINK-A IncRNA for early stage osteosarcoma. The area under the curve was 0.8877 , with standard error of 0.03549 and 95\% confidence interval of 0.8182-0.9673 ( $\mathrm{P}<0.0001$; Fig. 3). 
A

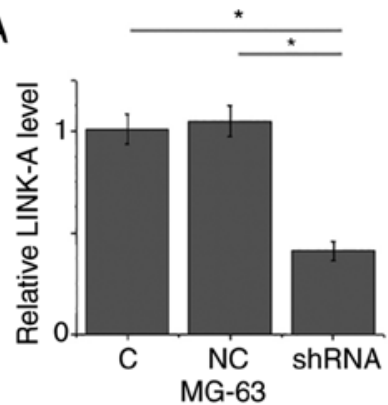

B
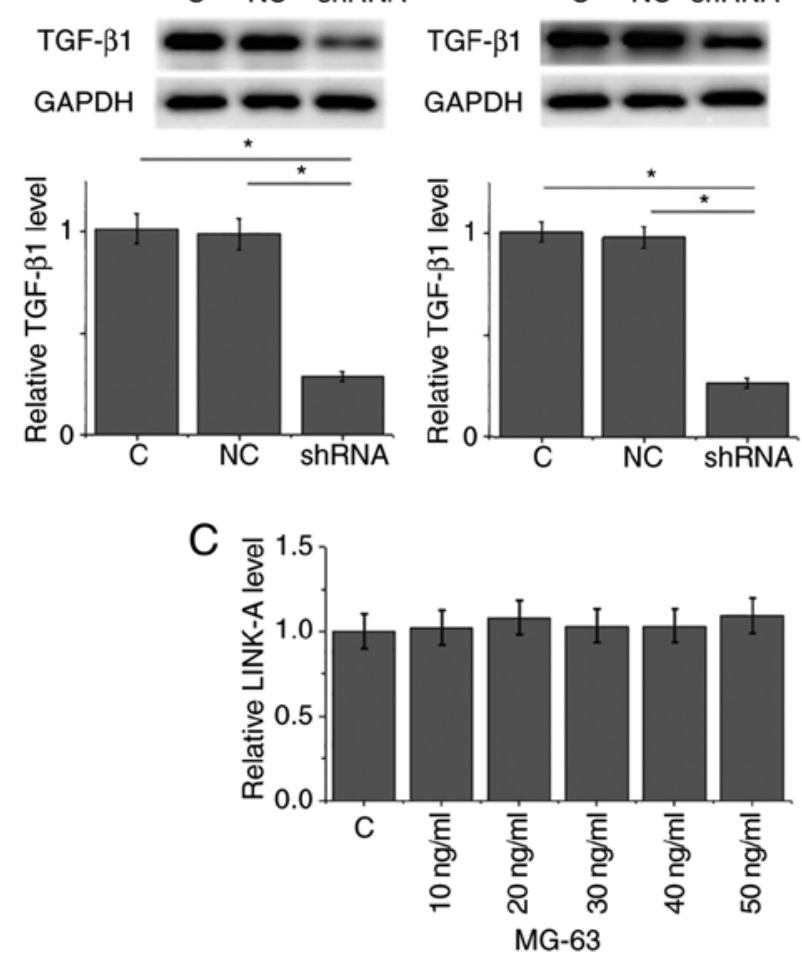
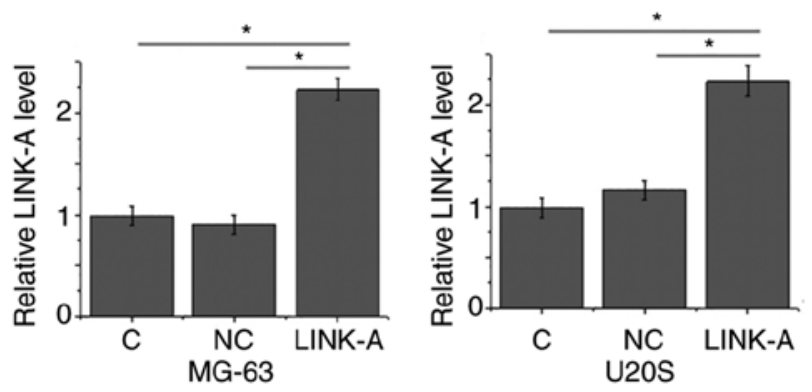

MG-63
C NC LINK-A

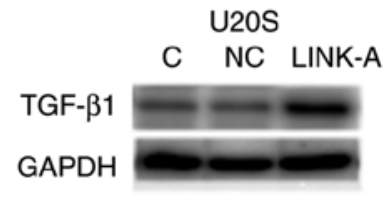

GAPDH
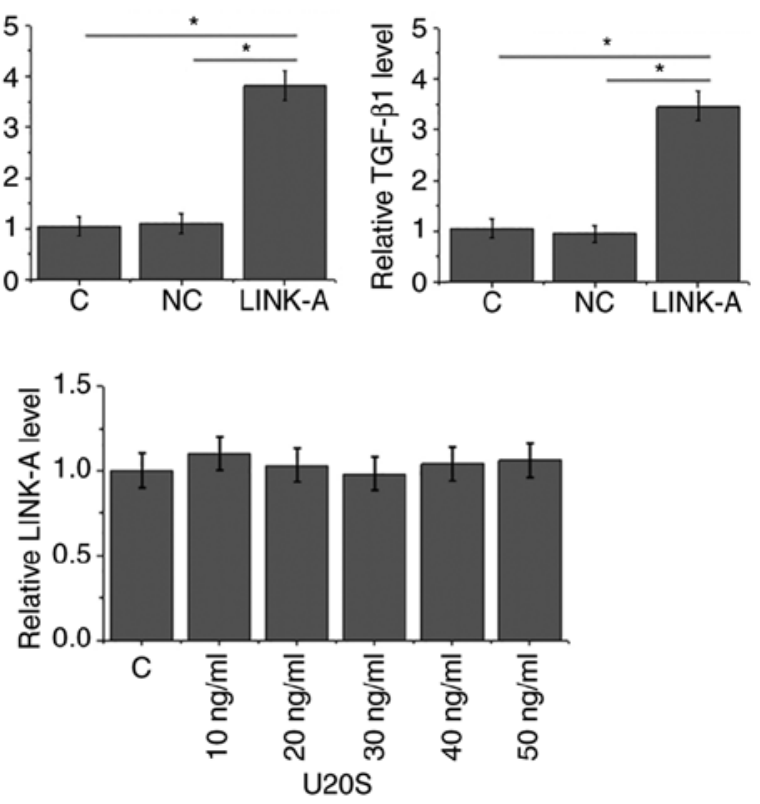

Figure 4. LINK-A lncRNA knockdown mediates TGF- $\beta 1$ inhibition in MG-63 and U2OS osteosarcoma cell lines. (A) LINK-A lncRNA knockdown and overexpression were achieved in MG-63 and U2OS osteosarcoma cell lines following transfection. (B) LINK-A lncRNA shRNA mediated the downregulation, whereas LINK-A lncRNA overexpression mediated the upregulation of TGF- $\beta 1$ in MG-63 and U2OS osteosarcoma cell lines. (C) TGF- $\beta 1$ treatment at doses of 10, 20,30, 40 and $50 \mathrm{ng} / \mathrm{ml}$ failed to significantly alter the expression of LINK-A lncRNA. *P<0.05. C, control; LINK-A, long intergenic non-coding RNA for kinase activation; lncRNA, long non-coding RNA; NC, negative control; TGF- $\beta 1$, transforming growth factor $\beta 1$.

LINK-A lncRNA positively regulates TGF- $\beta 1$ in $M G-63$ and U2OS osteosarcoma cell lines. RT-qPCR analysis was used to confirm that LINK-A IncRNA expression was decreased or increased following shRNA or overexpression vector transfection, respectively, in MG-63 and U2OS osteosarcoma cell lines compared with the control groups (Fig. 4A). LINK-A lncRNA shRNA mediated the downregulation, whereas LINK-A lncRNA overexpression mediated the upregulation of TGF- $\beta 1$ expression in the two osteosarcoma cell lines (Fig. 4B). By contrast, exogenous TGF- $\beta 1$ treatment at doses of $10,20,30$, 40 and $50 \mathrm{ng} / \mathrm{ml}$ failed to significantly alter the expression of LINK-A lncRNA in these cells (Fig. 4C).

LINK-A lncRNA knockdown inhibits migration, invasion and stemness of MG-63 and U2OS cells. Compared with the control groups, LINK-A lncRNA knockdown significantly inhibited, whereas treatment with TGF- $\beta 1$ at a dose of
$10 \mathrm{ng} / \mathrm{ml}$ significantly promoted the migration (Fig. 5A), invasion (Fig. 5B) and stemness (reflected by percentage of CD133+ cells; Fig. 5C) of cells of MG-63 and U2OS osteosarcoma cell lines. In addition, exogenous TGF- $\beta 1$ significantly attenuated the effects of LINK-A lncRNA knockdown (Fig. 5).

\section{Discussion}

LINK-A lncRNA is a recently characterized lncRNA with oncogenic functionality in triple-negative breast cancer and ovarian carcinoma $(12,13)$. The key finding of the present study was that LINK-A lncRNA may also be an oncogenic lncRNA in osteosarcoma and may participate in cell migration, invasion and stemness. The actions of LINK-A lncRNA were at least partially mediated by TGF- $\beta 1$.

It has been reported that the development of osteosarcoma affects the expression of a large set of genes in the human 
A

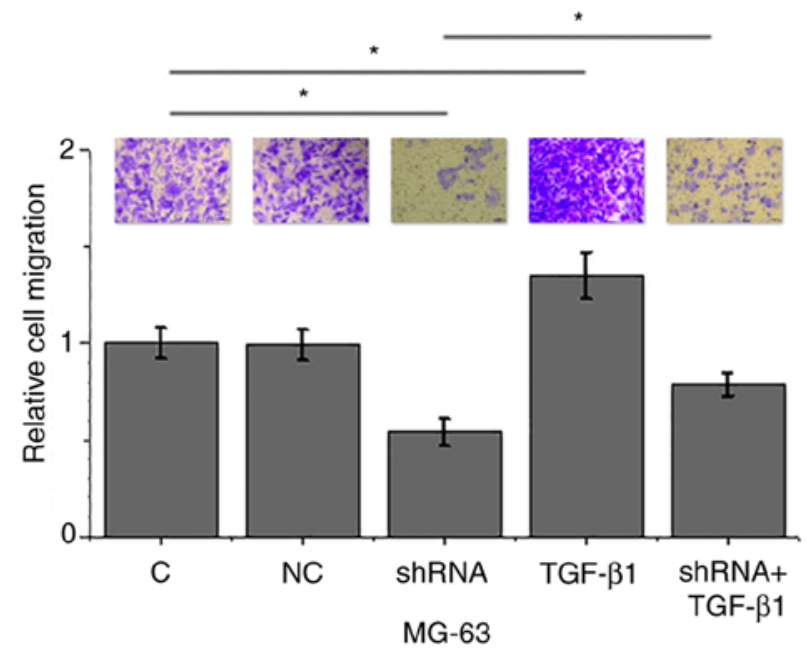

B

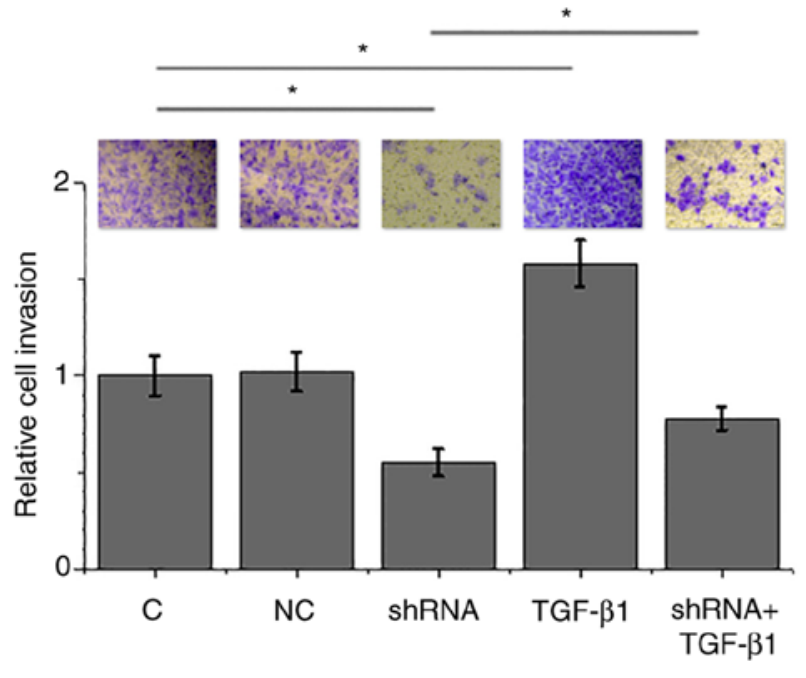

MG-63

C

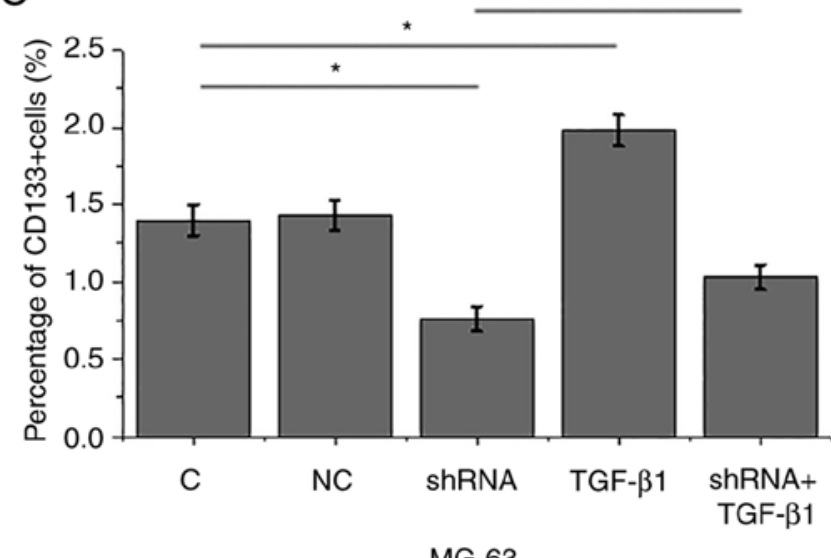

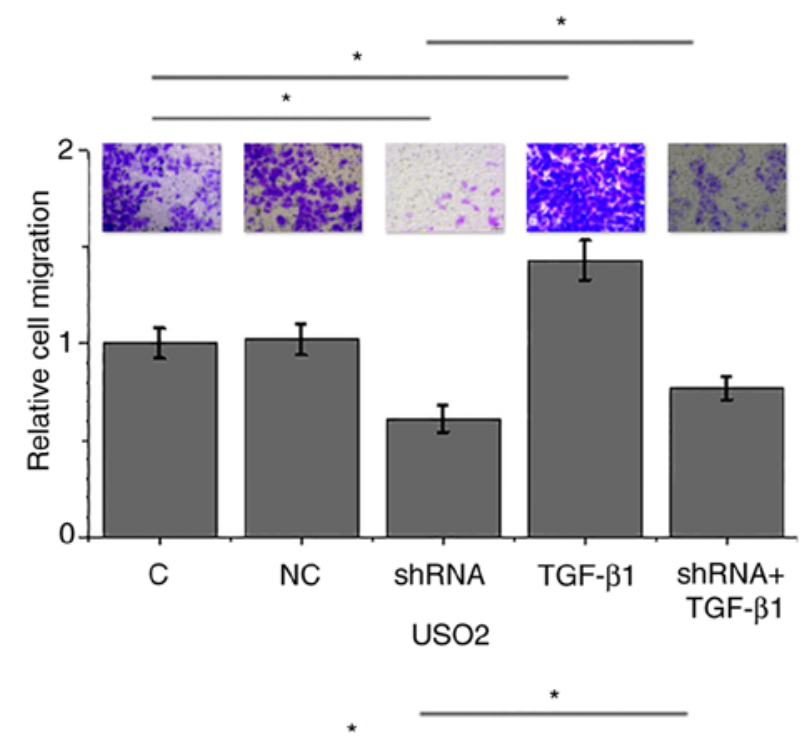

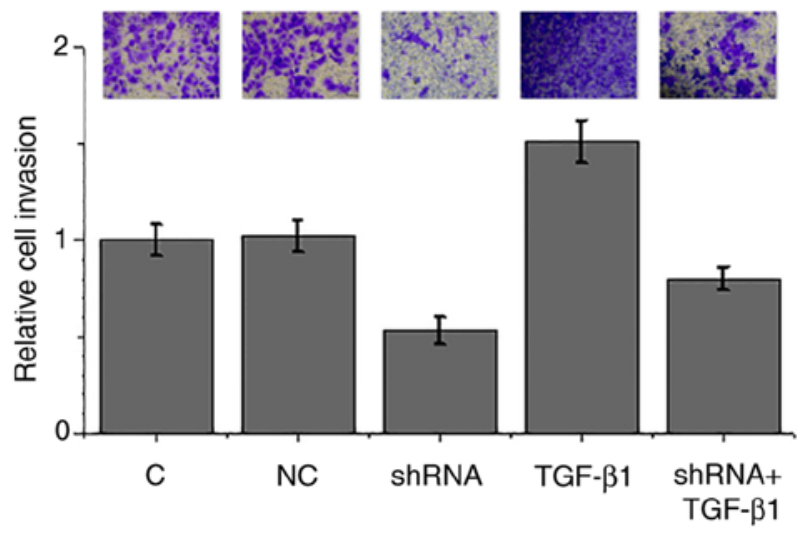

USO2

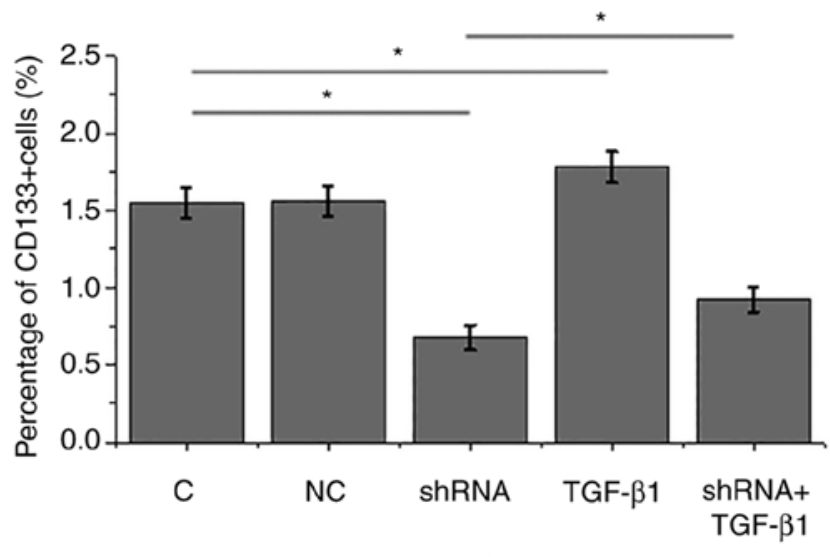

U2OS

Figure 5. LINK-A lncRNA knockdown mediates the inhibition of migration, invasion and stemness of MG-63 and U2OS osteosarcoma cell lines through TGF- $\beta 1$. (A-C) LINK-A lncRNA knockdown significantly inhibited, whereas treatment with TGF- $\beta 1$ (10 ng/ml) significantly promoted the (A) migration, (B) invasion and (C) stemness of cells of MG-63 and U2OS osteosarcoma cell lines. In addition, exogenous TGF- $\beta 1$ co-treatment significantly attenuated these effects of LINK-A lncRNA knockdown. For invasion and migration data, $\mathrm{C}$ group was set to ' 100 ' and all other groups were normalized to $\mathrm{C}$. "P<0.05. C, control; LINK-A, long intergenic non-coding RNA for kinase activation; lncRNA, long non-coding RNA; NC, negative control; TGF- $\beta 1$, transforming growth factor $\beta 1$.

body, including lncRNAs $(15,16)$. In the present study LINK-A IncRNA was significantly upregulated in plasma from patients with osteosarcoma compared with healthy controls. A recent study has demonstrated that LINK-A lncRNA is involved in the regulation of migration and invasion of ovarian carcinoma cells (13). The present study revealed that inhibition 
of LINK-A lncRNA inhibited migration and invasion and reduced stemness of cancer cells in osteosarcoma in vitro. Therefore, inhibition of LINK-A IncRNA may serve as a potential therapeutic target for osteosarcoma. It is also worth mentioning that inhibition of LINK-A lncRNA exhibited no significant effects on osteosarcoma cell proliferation (data not shown), which indicated that LINK-A IncRNA is unlikely to be involved in the regulation of proliferation of osteosarcoma, which is consistent with the previous study (13).

Early diagnosis is crucial for the survival of patients with osteosarcoma. The present study enrolled 26 patients with osteosarcoma at stages I and II. ROC curve analysis revealed that the upregulation of LINK-A IncRNA distinguished patients with early stage osteosarcoma from healthy controls. Therefore, circulating LINK-A IncRNA may be a potential marker for the early diagnosis of osteosarcoma. However, clinical trials are needed to further test the applicability.

Activation of TGF- $\beta$ is frequently observed in cancer development $(17,18)$. Inhibition of TGF- $\beta$ signaling is considered a promising therapeutic target for cancers (19). The present study also demonstrated significantly higher plasma levels of TGF- $\beta 1$ in patients with osteosarcoma compared with healthy controls. It is known that TGF- $\beta$ signals in cancer by interacting with lncRNAs $(10,11)$. The present study indicated that LINK-A lncRNA may be upstream of TGF- $\beta 1$ in the regulation of migration, invasion and stemness of osteosarcoma. As the plasma levels of LINK-A lncRNA and TGF- $\beta 1$ were revealed to be positively correlated in both osteosarcoma and healthy controls, the interaction between LINK-A IncRNA and TGF- $\beta 1$ is unlikely to be disease-specific. However, whether this interaction is direct or indirect is still unknown. LINK-A lncRNA overexpression and knockdown failed to affect TGF- $\beta 1$ expression at the mRNA level (data not shown); therefore, LINK-A lncRNA may affect TGF- $\beta 1$ accumulation or degradation, but not gene transcription.

In conclusion, LINK-A IncRNA and TGF- $\beta 1$ were both upregulated in osteosarcoma. LINK-A lncRNA may regulate TGF- $\beta 1$ to participate in the regulation of migration, invasion and stemness of cancer cells in osteosarcoma.

\section{Acknowledgements}

Not applicable.

\section{Funding}

No funding was received

\section{Availability of data and materials}

The datasets used and/or analyzed during the current study are available from the corresponding author upon reasonable request.

\section{Authors' contributions}

YK did the experiments, analyzed the data and was a major contributor in writing the manuscript. $\mathrm{ZN}, \mathrm{CM}$ and $\mathrm{HG}$ performed the experiments and literature reviews, and analyzed data. All authors read and approved the final manuscript and all authors should confirm its accuracy.

\section{Ethics approval and consent to participate}

Ethical approval was obtained from the Ethics Committee of Jining First People's Hospital, Shizhong, Jining, China. All procedures performed in studies involving human participants were in accordance with the ethical standards of the institutional and national research committees, the 1964 Declaration of Helsinki and its later amendments. Informed written consent was obtained from all patients and controls following an explanation of the nature and possible consequences of the study.

\section{Patient consent for publication}

Not applicable.

\section{Competing interests}

The authors declare that they have no competing interests.

\section{References}

1. Moreno F, Cacciavillano W, Cipolla M, Coirini M, Streitenberger P, López Martí J, Palladino M, Morici M, Onoratelli M, Drago G, et al: Childhood osteosarcoma: Incidence and survival in Argentina. Report from the national pediatric cancer registry, ROHA network 2000-2013. Pediatr Blood Cancer 64, 2017.

2. Durfee RA, Mohammed M and Luu HH: Review of osteosarcoma and current management. Rheumatol Ther 3: 221-243, 2016.

3. Anderson ME: Update on survival in osteosarcoma. Orthop Clin North Am 47: 283-292, 2016.

4. Berner K, Johannesen TB, Berner A, Haugland HK, Bjerkehagen B, Bøhler PJ and Bruland ØS: Time-trends on incidence and survival in a nationwide and unselected cohort of patients with skeletal osteosarcoma. Acta Oncol 54: 25-33, 2015.

5. Slade AD, Warneke CL, Hughes DP, Lally PA, Lally KP, Hayes-Jordan AA and Austin MT: Effect of concurrent metastatic disease on survival in children and adolescents undergoing lung resection for metastatic osteosarcoma. J Pediatr Surg 50: $157-160,2015$.

6. Nakao A, Afrakhte M, Morén A, Nakayama T, Christian JL, Heuchel R, Itoh S, Kawabata M, Heldin NE, Heldin CH and ten Dijke P: Identification of Smad7, a TGFbeta-inducible antagonist of TGF-beta signalling. Nature 389: 631-635, 1997.

7. Soderberg SS, Karlsson G and Karlsson S: Complex and context dependent regulation of hematopoiesis by TGF-beta superfamily signaling. Ann N Y Acad Sci 1176: 55-69, 2009.

8. Akhurst RJ and Derynck R: TGF-beta signaling in cancer-a double-edged sword. Trends Cell Biol 11: S44-S51, 2001.

9. Willis BC and Borok Z: TGF-beta-induced EMT: Mechanisms and implications for fibrotic lung disease. Am J Physiol Lung Cell Mol Physiol 293: L525-L534, 2007.

10. Mondal T, Subhash S, Vaid R, Enroth S, Uday S, Reinius B, Mitra S, Mohammed A, James AR, Hoberg E, et al: MEG3 long noncoding RNA regulates the TGF- $\beta$ pathway genes through formation of RNA-DNA triplex structures. Nat Commun 6: 7743 , 2015.

11. Li Z, Dong M, Fan D, Hou P, Li H, Liu L, Lin C, Liu J, Su L, Wu L, et al: IncRNA ANCR down-regulation promotes TGF- $\beta$-induced EMT and metastasis in breast cancer. Oncotarget 8: 67329-67343, 2017.

12. Lin A, Li C, Xing Z, Hu Q, Liang K, Han L, Wang C, Hawke DH, Wang S, Zhang Y, et al: The LINK-A IncRNA activates normoxic HIF1 $\alpha$ signalling in triple-negative breast cancer. Nat Cell Biol 18: 213-224, 2016.

13. Ma J and Xue M: LINK-A lncRNA promotes migration and invasion of ovarian carcinoma cells by activating TGF- $\beta$ pathway. Biosci Rep 38: pii: BSR20180936, 2018.

14. Livak KJ and Schmittgen TD: Analysis of relative gene expression data using real-time quantitative PCR and the 2(-Delta Delta C(T)) method. Methods 25: 402-408, 2001. 
15. Atiye J, Wolf M, Kaur S, Monni O, Böhling T, Kivioja A, Tas E, Serra M, Tarkkanen M and Knuutila S: Gene amplifications in osteosarcoma-CGH microarray analysis. Genes Chromosomes Cancer 42: 158-163, 2005.

16. Li JP, Liu LH, Li J, Chen Y, Jiang XW, Ouyang YR, Liu YQ, Zhong $\mathrm{H}, \mathrm{Li} \mathrm{H}$ and Xiao T: Microarray expression profile of long noncoding RNAs in human osteosarcoma. Biochem Biophys Res Commun 433: 200-206, 2013.

17. Solar M and Paul W: Chain relaxation in thin polymer films: Turning a dielectric type-B polymer into a type-A' one. Soft Matter 13: 1646-1653, 2017.
18. Hawinkels LJ, Paauwe M, Verspaget HW, Wiercinska E, van der Zon JM, van der Ploeg K, Koelink PJ, Lindeman JH, Mesker W, ten Dijke P and Sier CF: Interaction with colon cancer cells hyperactivates TGF- $\beta$ signaling in cancer-associated fibroblasts. Oncogene 33: 97-107, 2014.

19. Colak S and Ten Dijke P: Targeting TGF- $\beta$ signaling in cancer. Trends Cancer 3: 56-71, 2017.

(i) (9) This work is licensed under a Creative Commons Attribution-NonCommercial-NoDerivatives 4.0 International (CC BY-NC-ND 4.0) License. 